\section{Identidad(es) en tensión: la trama del mercado en los relatos audiovisuales recientes sobre tango}

Marisa Iris Alonso ${ }^{(1)}$

Resumen: En el presente artículo analizaremos un corpus de filmes producidos entre el 2001 y el 2010 que abordan el tópico del tango. Nos proponemos revisar la relación existente entre el mercado, las formas de producción y distribución de dichos filmes y las identidades que estos construyen en sus tramas.

Estudiaremos las diferentes fuentes de financiamiento a las que accedieron y los lugares de circulación, deteniéndonos en particular en los festivales internacionales de cine que, desde la primera mitad de los años ochenta, sumaron a la función tradicional de exhibidores la de productores, incursionando también en labores industriales (Soria, 2016; Amiot, 2018).

Las preguntas que guían el trabajo son: ¿Dónde y de qué manera circularon los filmes argentinos sobre tango? ¿En qué medida la ayuda técnica y económica brindada por las distintas organizaciones internacionales condicionaron los contenidos de estos filmes? ¿Qué criterios de selección existieron a la hora de financiar nuevos proyectos y cómo impactaron en las producciones locales? ¿Qué relaciones pueden establecerse entre el financiamiento y las identidades/alteridades que allí se construyeron?

Palabras clave: identidad - mercado - cine - tango - relato audiovisual.

[Resúmenes en inglés y portugués en la página 135]

(1) Profesora en Enseñanza Media y Superior en Historia (UBA-FFyL). Maestranda en Teoría y Estética del Arte (UNLP). Profesora adjunta regular en la Universidad Nacional de Quilmes. Integra el comité editorial del Boletín de Estudios sobre Activos Culturales (FCE-UBA). Es investigadora del Centro de Estudios en Historia, Cultura y Memoria (CEHCMe-UNQ). 


\section{Introducción}

Estudiar la representación del tango en el cine implica necesariamente reflexionar sobre un fenómeno social y cultural, ya que tanto la danza como la música muy tempranamente tuvieron un protagonismo notable en las producciones nacionales e internacionales.

Durante la década de los noventa, la determinación de las agencias nacionales, el Estado nacional primero y en segundo lugar el Estado municipal, de intervenir en el pasado y la memoria y patrimonializar ${ }^{1}$ al tango abrieron un proceso cuyos intereses en pugna nos ofrecen indicios de un tiempo y un espacio político-social determinado. En 1991 la Ley 23980 creó la Academia Nacional del Tango que tenía entre sus principales objetivos promover el tango en el país y en el exterior, organizar el Museo del Tango y patrocinar centros de estudios y difusión. En 1996 una nueva ley, la 24684², convirtió al tango en patrimonio cultural argentino. Dos años más tarde, en 1998, la ciudad de Buenos Aires, mediante la Ley 130, reconoció al tango como patrimonio de la ciudad y garantizó la difusión, promoción y recuperación de todas las expresiones vinculadas a este. Asimismo, se comprometió a subsidiar y/o subvencionar, incluso facilitando y promoviendo adhesiones, a asociaciones sin fines de lucro que ayudaran a difundirlo ${ }^{3}$. El tango pasó de ser aquella música y su danza que habían prácticamente desaparecido durante la segunda mitad del siglo $\mathrm{XX}$, como parte de un proceso de transformación en el consumo de productos musicales, a convertirse en un objeto cultural vital y dinámico. La década de los noventa significó para el tango un reposicionamiento, producto de esta legislación que describimos, y una revalorización asociada a las posibilidades que ofreció como objeto cultural capaz de ser consumido en el mercado global (Cecconi, 2014; Morel, 1999, 2003, 2009).

El proceso de desintegración social y política que ocurrió a partir del 2001 en la Argentina encontró en el ámbito cultural una forma de resistencia a la aguda crisis. El tango participó activamente de esta situación.

En este contexto, surgieron una serie de movimientos culturales, organismos, asociaciones y compañías de baile centradas en el tango, que buscaban hacer frente a la situación de pérdida de sentido que la sociedad atravesaba. Como observa Sofía Cecconi (2017):

De esta manera, el clima de movilización que se propagó con la crisis del 2001 impregnó muchas de las manifestaciones juveniles ligadas al tango. La protesta, la autogestión y la cooperación se anudan en la práctica de estos jóvenes a una recuperación del tango que viven como una revancha histórica de la cultura local frente al menosprecio que ella había sufrido a lo largo de la década anterior. En el tango estos jóvenes encuentran la posibilidad de plasmar un posicionamiento político, contrario al que fue dominante durante los noventa y afín a las luchas que irrumpen cuando la situación social eclosiona, pero también de reivindicarse como colectivo, como parte de una generación que se apropia de la tradición para reinventarla con un lenguaje propio [...] con la crisis se expresa en esta organización conformada por un colectivo de músicos, cantantes, bailarines y periodistas que procuran "una mejor distribución de las políticas culturales y de los fondos estatales” destinados al género (p. 166). 
Nuestra hipótesis es que, a partir de la crisis social y política del 2001, el tango se transformó en un objeto identitario capaz de construir un puente con el pasado pero que se resignificaba en un presente transformado por el proceso desatado por dicha crisis. Los nuevos relatos audiovisuales pos-2001 lograron armonizar ese vínculo entre pasado, tradición y contexto. El tango se transformó en una práctica cultural que contenía la mixtura del arraigo en la historia y su relación con el presente, que recuperaba un sector de la sociedad que decidía resistir a la crisis a través de esa reapropiación. Los jóvenes fueron, en general, los protagonistas de este nuevo relato.

En palabras de Cecconi (2017):

[...] el tango también empieza a ser considerado [...]: un tesoro hundido que otros jóvenes emprenden la aventura de recuperar de las profundidades de la historia, aliándose para ello con una generación de músicos que bien podrían ser sus abuelos. [...] todos estos jóvenes vuelcan su mirada hacia atrás, en una especie de fuga hacia el pasado, como si emprendieran la búsqueda de un sentido para el cual las voces del presente no tuvieran respuestas satisfactorias ( $\mathrm{p}$. 167).

Para el presente trabajo hemos definido y visionado un total de quince películas producidas entre el 2001 y el 2010 que abordan el tópico del tango: Notas de tango (Rafael Filippe1li, 2001), Bar El Chino (Daniel Burak, 2003), Yo no sé qué me han hecho tus ojos (Lorena Muñoz y Sergio Wolf, 2003), Abrazos, tango en Buenos Aires (Daniel Rivas, 2003), Tango, un giro extraño (Mercedes García Guevara, 2005), El último bandoneón (Alejandro Saderman, 2005), El sur de una pasión (Cristina Fasulino, 2005); Si sos brujo: una historia de tango (Caroline Neal, 2005), Garúa (Gustavo Corrado, 2007), El tango de mi vida (Hernán Belón, 2008), Café de los maestros (Miguel Kohan, 2008), La cantante de tango (Diego Martínez Vignatti, 2009), Homero Manzi, un poeta en la tormenta (Eduardo Spagnuolo, 2009), El último aplauso (Germán Kral, 2009) y El Torcan (Gabriel Arregui, 2009).

Las preguntas que guían el análisis son las siguientes: ¿Dónde y de qué manera circularon los filmes argentinos sobre tango? ¿En qué medida la ayuda técnica y económica brindada por las distintas organizaciones internacionales condicionaron los contenidos de estos filmes? ¿Qué criterios de selección existieron a la hora de financiar nuevos proyectos y cómo impactaron en las producciones locales? ¿Qué relaciones pueden establecerse entre el financiamiento y las identidades/alteridades que allí se construyeron?

La propuesta no solo se concentrará en las representaciones, sino que saldrá de ellas hacia los contextos de producción en que fueron desarrolladas, lo que permitirá evidenciar cambios, continuidades y reconfiguraciones. El análisis de esos interrogantes se abordará a partir de los textos fílmicos, así como también de la información histórico-social de la que disponemos. 


\section{El contexto social y político. Una referencia a la crisis del 2001}

Desde el 2001 en adelante se filmaron una importante cantidad de películas que tuvieron como protagonista al tango. Muchos de los relatos que contienen estos filmes están asociados a los acontecimientos que se produjeron como efecto de la crisis que azotó la Argentina en esos años. El 2001 significó "la alteración del sentido del tiempo histórico" (Sztulwark, 2019, p. 14); una búsqueda de valores y bienes culturales que pudieran aproximar respuestas a los hechos trágicos vividos. Dichos acontecimientos se convirtieron en una coyuntura única no solo por la profundidad de la crisis económica, sino por la disolución de los vínculos políticos y sociales que pusieron en jaque el poder del Estado nacional. El colapso del aparato productivo, bancario y de las finanzas públicas fue la expresión más evidente del derrumbe. Se trató de una oportunidad para observar lo que podemos denominar como "la explosión cultural en la crisis" (Marchini, 2007, p. 29). En ese contexto, el tango obtuvo una mayor legitimidad cultural que la que había tenido desde la segunda mitad del siglo XX hasta los años noventa. Se convirtió en una opción cultural desde la cual era posible recuperar sentidos enraizados en el pasado y más estrechamente relacionados con los deseos y los intereses que en ese momento tenían los sujetos.

El reto que asumieron los directores de los filmes que se produjeron en estos años fue el de presentar historias que contaran la trágica realidad que se estaba viviendo y que pudieran comercializarse en el mercado internacional (Rocha, 2008). Esto fue lo que ocurrió, particularmente, con los relatos audiovisuales vinculados al tema del tango que conforman nuestro corpus.

Los medios de prensa del período fueron los que dieron cuenta de la importancia económica que alcanzó en esta etapa el tango como objeto de consumo global. En una situación tan compleja como era la de la Argentina de esos tiempos, este hecho se volvió más relevante y se destacó como una herramienta económica más para salir de la crisis.

Hay numerosos ejemplos de estos contenidos desarrollados en los distintos medios de prensa del momento. Para mencionar algunos de ellos, presentamos los siguientes:

El tango es un producto cultural y en su exportación intervienen en distintos planos y en forma desordenada muchos actores. Pero al revés de lo que sucede con otros productos, este caso no hay que salir a buscar mercado. Al tango lo están esperando. Y es la única marca por la que se identifica en todos lados a la Argentina. Los más entusiastas piensan que se puede repetir la historia de Inglaterra: el principal ingreso del país de la revolución industrial proviene de los discos de Los Beatles y los de los Rolling Stones (Clarín, 10 de diciembre del 2000).

En julio del 2008, otro diario de circulación masiva, desarrolló la siguiente nota, bajo el título "Tendencias. Tango S.A.": 
El año pasado generó 400 millones de pesos. Y es una industria que no para de crecer. Cómo y quiénes son los protagonistas de este fenómeno que sigue transformando a Buenos Aires, y convoca cada vez a más sectores para deleitar a argentinos y extranjeros.

[...]

La última encuesta sobre turismo internacional elaborada por la Secretaría de Turismo de la Nación (Sectur) y el Instituto Nacional de Estadística y Censos (Indec) dice que los extranjeros que ingresaron al país en febrero a través del aeropuerto internacional de Ezeiza gastaron 23,1\% más que el año pasado. Según el Ente Turismo de Buenos Aires (GCBA), casi un 17\% de los turistas no argentinos consumieron tango. Sumemos a eso los cruceros: esta temporada arribaron 99 buques a la Terminal Benito Quinquela Martín y ya hay confirmados 124 para 2009. Todo conspira para que la matemática sea, en un futuro, cada vez menos exacta: $2 \times 4$ va a dar 400 millones. O más (Pizarro, 27 de julio de 2008, La Nación).

Vinculado al fenómeno económico al que hacían referencia los medios de comunicación escrita, las películas que se filmaron sobre la temática del tango después del 2000 casi duplicaron las de la década anterior. Durante la década de los noventa, hemos identificado un total de siete películas; de las siete, cinco fueron filmadas el mismo año en que se aprobó la ley nacional de patrimonializacion del tango ${ }^{4}$. Entre los años 2003 y 2005 se estrenaron un gran número de filmes. Las dimensiones del fenómeno que describimos se ponen en evidencia en la nota del diario La Nación de noviembre del 2003 que aquí transcribimos:

El cine vuelve a poner la lupa en el tango. Desde los años de oro del cine nacional, cuando el género musical y sus figuras ocupaban la pantalla grande, la temática tanguera había aparecido con cuentagotas en los últimos años, a partir de algunos films extranjeros como La lección de tango, de Sally Porter, la película Tango, de Carlos Saura [...] Bar El Chino, de Daniel Burak, ambientada en el mítico reducto de Pompeya; las debutantes Yo no sé qué me han hecho tus ojos, sobre la vida mítica de la cancionista Ada Falcón; Abrazos, tango en Buenos Aires, registro del último Festival Buenos Aires Tango, y Tango, un giro extraño, sobre los nuevos intérpretes del género, que está en posproducción. En todos esos largometrajes el tango vuelve a ser objeto de culto, a través de la ficción o el documental, como reflejo de un imaginario colectivo que ya no existe, como registro de un fenómeno actual, como forma de retratar el espíritu y la pulsación de una ciudad, o como excusa para ambientar una historia de amor o reflejar a una Argentina en crisis (Plaza, 20 de noviembre de 2003).

Dos años después, en noviembre del año 2005, nuevamente la prensa escrita hizo referencia a dos estrenos sobre tango el mismo jueves: El sur de una pasión y Tango, un giro extra- 
ño (Página 12, 22 de noviembre de 2005). Todo lo cual da cuenta de una situación que llamaba la atención en este contexto político y social de crisis al que nos estamos refiriendo.

\section{Producción, circulación y mercado}

Este aumento de filmes está asociado al proceso que tiene que ver con la transformación en las tecnologías que facilitó la posibilidad de filmar. Pero también, como venimos observando, está relacionado con los procesos sociales y políticos que describimos aquí.

El Estado, a través de las legislaciones (particularmente, la Ley 24377/94 y más tarde las modificaciones realizadas a la Ley 17741 en el 2004), estimuló la producción audiovisual con la ampliación de la cuota de pantalla y la media de continuidad (Soria, 2016, p.16), garantizando de esta manera la reactivación de la industria, la distribución y exhibición. Sin embargo, después de la crisis del 2001 y mientras que la economía empezó su lenta reactivación, la concurrencia a las salas del público se mantuvo en un nivel relativamente bajo debido a la crítica situación del contexto ${ }^{5}$. Esto explica que la mayoría de los filmes que analizamos circularan especialmente en festivales. Esta posibilidad les aseguraba acceder a un cierto nivel de público como, por ejemplo, estudiantes de cine, especialistas en la temática, académicos y productores.

Una parte de los filmes que conforman el corpus con el que trabajamos son coproducciones: El último bandoneón, 2003; Abrazos, tango en Buenos Aires, 2003; Café de los maestros, 2008; La cantante de tango, 2009 y El último aplauso, 2009. La coproducción permite ganar fuentes de financiamiento complementarias e incrementar la difusión de las películas más allá de las fronteras nacionales. La mayoría de estos filmes fueron producidos por productoras independientes; como ejemplo, podemos mencionar a Cine Ojo, que produjo el filme Yo no sé qué me han hecho tus ojos, de Muñoz y Wolf. Si bien todas recibían el aporte del INCAA ${ }^{6}$ (Instituto Nacional de Cine y Artes Audiovisuales), podemos sospechar que este resultaba insuficiente; por eso, como una característica de la época, los directores siempre buscaban otras fuentes de financiamiento que se podían obtener para hacer viable el proyecto.

Estudiar las formas del financiamiento en los filmes del pos-2001 implica indagar en la relación entre estos y los criterios de producción. El financiamiento por parte de las instituciones, organismos internacionales, fundaciones, etcétera, implicaba que los proyectos seleccionados debían tener determinadas características. En el caso del corpus con el que trabajamos, la Fundación Huber Bals fue la que aportó fondos para la realización de por lo menos tres de estos filmes: El sur de una pasión (2005), Garúa (2007) y La cantante de tango (2009). Esta fundación cuenta con un programa de subsidios destinado a fomentar la producción cinematográfica en regiones periféricas (Campos Rabadán, 2016) ${ }^{7}$. Dicho modelo de financiamiento se complementa muchas veces con subsidios del Estado o de entidades privadas.

Un ejemplo de la presencia de esta forma de financiamiento lo podemos observar en el filme El sur de una pasión (2005) de Cristina Fasulino. El filme narra la historia de Susan que es hija de un tanguero en decadencia. Ambos trabajan en un club nocturno, donde forman una pareja de tango. Los une una relación incestuosa que da un vuelco cuando 
él va a la cárcel. La directora presenta su relato en un contexto de crisis económica, los protagonistas viven en una pensión y pasan necesidades. Prostitución, marginalidad, sexualidad prohibida y tango, todos estos condimentos forman parte del relato. Este filme no solo recibió la ayuda de la Fundación Huber Bals, sino también el apoyo del Ministerio de Asuntos Exteriores de Francia en un proyecto que se conoció como Fond du Sud; un fondo especialmente creado en los años ochenta, en un clima político y cultural en Francia que promovía la diversidad y la necesidad de que una nación con una tradición cultural y cinematográfica como la francesa se posicionara en el mercado de cine de autor, considerado un tipo de cine artístico con cierto prestigio. El objetivo era financiar a los países vulnerables para evitar la embestida del cine de los Estados Unidos que arrasaba con su participación, impidiendo otras posibles participaciones en el mundo de la distribución y el consumo de cine.

La Argentina fue uno de los países que más recibió este tipo de financiamiento; según Amiot (2018), obtuvo unas cuarenta subvenciones entre 1985 y 2011. A modo de comparación, China, que le sigue justo detrás, contó con la ayuda a veintisiete películas. Esto muestra la habilidad de los productores argentinos para presentarse en este tipo de subsidios. Si seguimos la cronología en que estas ayudas fueron acordadas en Argentina, se observa que la mayoría se concentran a mediados de los años 2000. Mientras que en el lapso que va desde 1981-1997, Argentina envía solo ocho películas, entre 1998 y 2011 se envían un total de 303 filmes. Nos encontramos, pues con una sobre-representación de la Argentina que repercute en la cantidad de proyectos subvencionados; a modo de ejemplo, entre el 2003 y el 2006 se subvencionaron cinco películas argentinas (Amiot, 2018).

Después del 2001, gran parte de los directores jóvenes asumieron las nuevas condiciones del mercado y reconocieron la necesidad de recurrir a fuentes de financiamiento diversas. Los fondos eran siempre escasos y la mayoría logró una expertise para poder alcanzar la concreción de su proyecto. Es cierto que ninguno de estos fondos cubría la totalidad del costo de la producción, con lo cual lo que aprendieron a hacer estos realizadores jóvenes fue a construir una red de mecanismos para poder costearla.

La particularidad de estas ayudas financieras que provienen de organizaciones u organismos del exterior es que, a menudo, contribuyen a determinar las estéticas de estos filmes, independientemente de su procedencia de origen (Soria, 2016). El criterio de selección de la Fundación Huber Bals señalaba, hasta el año 2016 en el que se produjo un cambio de políticas, que los filmes que estaban en condiciones de recibir el financiamiento debían ser

[...] originales, auténticos y estar arraigados en la cultura de los países solicitantes, a la vez que deben contribuir al desarrollo de la industria del cine local como de las habilidades de sus realizadores. [...] la condición para que los films reciban la ayuda financiera que solicitan reside en que sus historias e imágenes sean representativas de su cultura nacional, que permitan comprender la historia, las costumbres y las tradiciones de su país (Soria, 2016, párr. 12).

Minerva Campos Rabadán (2012, 2013), que ha estudiado el tema de los festivales, observa que existe una diversidad en los filmes seleccionados por dicha fundación y también es 
diversa la procedencia de estos. A la vez, es factible identificar características recurrentes en esta filmografía. Así, por ejemplo, los temas sociales que se relatan están relacionados con historias individuales; por su parte, las características de los personajes principales presentan una tendencia a reiterarse. Lo personal y biográfico es una de las características más evidente. Lo que plantea su investigación, junto con otras que abundan en el mismo sentido, es que estos financiamientos configuran narrativas, formas de distribución y de consumo en el mercado (Soria, 2016; Amiot, 2018). En general, hay una combinación entre un relato más centrado en el contenido de lo local que convive con temas que son de naturaleza universal. ${ }^{8}$

En nuestro corpus, el tema de lo local está presente a través de la música, la danza o la poesía tanguera que tiene como escenario a la ciudad de Buenos Aires. Una metrópolis actual en la cual aparece la miseria, la pobreza, lo marginal. De Buenos Aires podemos ver sus calles, sus bares, el suburbio y sus características. Como ejemplos de lo que decimos podemos mencionar a Bar El Chino (2003), El último aplauso (2009) y Garúa (2007). Hay una melancolía, una nostalgia que envuelve la mayor parte de las creaciones y que está vinculada al tango en tanto una música que refiere $\mathrm{eso}^{9}$. Los personajes son mayoritariamente hombres y mujeres jóvenes que transitan innumerables dificultades para alcanzar la realización personal en una ciudad que forma parte de un país en crisis. La falta de oportunidades de trabajo, como las que enfrenta Jimena, la protagonista de Bar El Chino, por ejemplo; la necesidad de lograr sortear las dificultades para hacer aquello que deseamos como Marina Gayoto, la bandoneonista joven que busca un instrumento en mejores condiciones que el que posee para sumarse a la orquesta de tango que organizó Rodolfo Mederos ${ }^{10}$ en El último bandoneón; o la historia de un amor contrariado que se vuelve una obsesión, como el que vive Helena la protagonista femenina de La cantante de tango. Cada uno de estos filmes reconstruye historias personales, individuales que podrían ser la de cualquier joven o adulto en cualquier lugar del mundo.

\section{Directores e identidad(es)}

Los directores de estas películas pueden compararse por tener ciertos aspectos biográficos y artísticos comunes. Cada uno de ellos tiene un relato particular por el que llega al tango, pero existen aspectos de ese relato que se comparten. Algunos de ellos vivían afuera, volvieron a la Argentina y filmaron sobre tango. Como ejemplos podemos mencionar a Daniel Burak (Bar El Chino, 2003), quien vivió y se formó en el exterior (Tel Aviv, Israel) y en un viaje a Buenos Aires su productor le sugirió conocer el mítico bar de El Chino en Pompeya y convertirlo en el punto de partida de un guion. Un relato posible sobre un tema local pero que en definitiva es un relato, como él mismo manifiesta en un diálogo con La Nación, "sobre el desarraigo, el valor de la amistad y el amor, tanto el filial como el sexual" (Montesoro, 14 de octubre de 2003). Germán Kral (El último aplauso, 2009) también se fue de la Argentina joven, estudió en Munich, discípulo de Win Wenders, volvió a 
la Argentina y eligió filmar sobre este bar y su dueño (Sendrós, 3 de diciembre de 2009). Alejandro Saderman (El ultimo bandoneón, 2005), quien vivió en Venezuela, regresó a la Argentina y a partir de su amistad con Rodolfo Mederos realizó su filme que reconstruye algunas particularidades del bandoneón y los bandoneonistas. Otros argentinos, desde el exterior, aprovecharon las conexiones y los contactos para filmar sobre el tango, como es el caso de Diego Martínez Vignatti (La cantante de tango, 2009), quien emigró de la Argentina en la década de los noventa y eligió filmar sobre el tango como una forma de reencontrarse con su país, de hecho este fue su tercer filme y tanto en el primero como en este abordó la temática del tango.

Las declaraciones que estos directores realizaron a los diferentes medios refiriéndose a sus producciones aportan una perspectiva sobre cómo definen al tango que relatan en sus filmes. Hernán Belón, el director de El tango de mi vida (2008), declaró en el diario Página 12:

Yo vivo en San Telmo desde hace muchos años y vi el boom de los turistas, por eso me daban ganas de hacer una película sobre el verdadero tango. $\mathrm{Mi}$ familia es de Monte Grande y de Lanús, me interesa el tango que se baila y se canta ahí, en las casas, en las sociedades de fomento [...] Tengo 38 años y cada vez me pegan más las letras del tango. Alguien decía en la película 'el tango es la vida en tres minutos' y es así, hay una síntesis, cosas bastantes profundas, a veces incluso exagerados, tangos que tienen cien años y siguen siendo representativos, porque tienen que ver con la idiosincrasia argentina, que es un poco llorona, un poco depresiva (Halfon, 1 de febrero de 2009). [La negrita me pertenece].

Martínez Vignatti también respondió a la pregunta sobre lo que significaba este género musical en su vida:

[...] el tango me pegó muy fuerte a partir de los 18 años, al igual que todo lo que tiene que ver con la poesía tanguera. El tango excede lo meramente musical y por supuesto que también a la danza. Es un sentimiento y también una sensación. Tiene que ver con cómo la gente habla y camina, con el aire que se respira en estas ciudades, los adoquines... El tango está en todos lados: en dos tipos comiendo una pizza a las $\mathbf{3}$ de mañana, en el canillita e incluso hasta en la protesta social. Todo eso me conmueve, me emociona y, además, me parece de una riqueza vastísima a nivel intelectual (Ranzani, 9 de noviembre de 2010). [La negrita me pertenece].

Por su parte, Cristina Fasulino, directora de El Sur de una pasión, sobre el tema de su película dijo que:

[...] El imaginario del tango se conforma sobre la base de ciertas constantes: la soledad, la marginalidad, la promiscuidad, el fracaso. Los personajes...Son 
descendientes de inmigrantes que no terminan de enraizarse. Poseen la nostalgia de la tierra lejana, el deseo de "lo otro". (Martínez, 22 de marzo de 1997).

En tanto, Carolina Neal, directora estadounidense radicada en Argentina, habló sobre los rasgos del tango con los que se identifica:

[...] Me siento identificada con su complejidad musical, su manera de contener en tres minutos tantos elementos distintos-el drama, la pasión, la tranquilidad, la belleza, la nostalgia, la sensualidad. En el baile, me encanta el lenguaje corporal sensual [dice refiriéndose a la danza]. Una conversación sin el obstáculo de palabras. Bueno, además soy inmigrante acá [se refiere a la Argentina], entonces algo en el tango me conecta con los inmigrantes que hace más de 100 años atrás alimentaron el género joven con sus experiencias de aventura y desarraigo (Arahuete, 28 de septiembre del 2015).

Por último, Gustavo Corrado, el director de Garúa, luego de observar que el tema del tango que da el nombre a su filme es solo una inspiración, indicó:

[...] el filme de algún modo es como una letra de tango, tiene todos sus elementos: la lucha por el honor, por el amor, la lucha con cuchillo, la marginalidad, la melancolía, la soledad (La Prensa, 13 de junio de 2007).

Las declaraciones de estos directores a los medios de prensa dan cuenta de cómo pensaban al tango para representarlo en imágenes. Todo lo que aquí se desarrolla y plantea está vinculado a las imágenes que estos filmes presentan.

El relato audiovisual relaciona el pasado con el presente del tango y ofrece una versión notablemente distinta a la que hemos analizado en la década de los noventa (Alonso 2016, 2018 y 2019). Hay un contenido nuevo, resignificado, vinculado al contexto y con una perspectiva diferente. Un guiño cultural a la historia del que pueden apropiarse algunos buscando una bohemia que represente una identidad local, redefinida por el contexto social y político.

Los ambientes en los que se filmaron estas películas son generalmente ambientes cotidianos: las casas de los protagonistas de los filmes, la sala de ensayo de los músicos, los camarines de los cantantes que van a salir a escena como es el caso de Bar El Chino (Daniel Burak, 2003) o el Tango de mi vida (Hernán Belón, 2008). En la mayoría de estos filmes el lugar del bar como espacio de contención, de referencia, de identidad es un tópico presente. En el bar se encuentran para festejar el cumpleaños del protagonista masculino de Bar El Chino que es, además, un bar icónico del barrio de Pompeya ${ }^{11}$; pero también en el bar se encuentra Helena, la protagonista de La cantante de tango, con su pareja y el mozo le trae lo de siempre; en el bar La Casona de Fernando se desarrolla El tango de mi vida (Belón, 2008), por dar solo algunos ejemplos. En estos filmes el bar es un espacio de refugio, un ámbito opuesto a la indiferencia producida por la aceleración de los tiempos y de las 
demandas, es el lugar en el que se encuentran los amigos, desde el que se observa la ciudad. En el bar, en general, lo que ocurre es la contraposición de lo que sucede en la sociedad poscrisis. Los lazos entre los que habitan el lugar son sólidos, mientras que el afuera, la calle, es hostil, individualista y conflictiva. Los filmes que se produjeron durante estos años ponen en escena aspectos de una nación por la cual pasó tanto el modelo neoliberal como la globalización, lo que dio como resultado la transformación y la modificación total o parcial de la vida cotidiana de sus habitantes.

El tango que se baila y que se escucha es el de antes pero también es el tango nuevo. Un ejemplo es Garúa (Corrado, 2007). Este film relata la historia de un cantante de tango que es asesinado por Franco, un joven que vive en un ambiente delictivo y de pobreza, que atormentado por la culpa de su delito inicia un camino que lo llevará a ocupar el lugar del artista desaparecido. El título del filme refiere a un tango tradicional de la década de los cuarenta ${ }^{12}$, pero la música, el ambiente y lo que ocurre refieren a una sociedad y a unos protagonistas que tienen características de marginales en una ciudad atravesada por la crisis. Es un tango dinámico, presente, representativo de lo tradicional, pero también de una juventud que se encuentra, porque se apropia y lo reinterpreta, en esos sonidos y esa música.

\section{Conclusiones preliminares}

“[...] el 2001 fue leído como irrupción de una temporalidad intempestiva: maldición o milagro" (Sztulwark, 2019).

Hemos identificado y caracterizado las formas de producción y circulación de las películas que son parte de nuestro corpus del pos-2001. Abordamos las relaciones que es posible establecer entre los festivales y los fondos de ayuda que permiten definir relatos temáticos y estéticos, además de un mapa de las formas de circulación que tienen estas producciones con vistas a alcanzar el mercado global.

La formación y el recorrido profesional y personal de los directores de estos filmes también ayudan a comprender cómo definen el relato audiovisual que hacen sobre el tango en este momento histórico que hemos delimitado. Podemos afirmar que los filmes pos-2001 recuperan el tango desde una perspectiva original; dicha originalidad está relacionada con que no se trata únicamente de relatar un tango for export sino que se hurga en el tiempo ${ }^{13}$ para encontrar un tango que, sin perder aquello que fue, se resignifique en una sociedad diferente. Directores jóvenes, o no tanto, buscan en esa música y en su danza -propia de la urbe porteña- un nuevo relato audiovisual, capaz de reflejar una sociedad del siglo XXI, en un contexto de predominio del mercado, de desintegración del Estado, de reformulación de los vínculos intersubjetivos. La búsqueda es con la ansiedad de encontrar ese puente entre el pasado y el presente; la necesidad de reconstruir la trama, el lazo, una forma de entender la cotidianidad. Hay algo reparador en esta música y esta danza de la ciudad de Buenos Aires y es por eso que eligen abordarla en sus filmes. Como reflexionó 
la directora Caroline Neal (Arahuete, 28 de septiembre 2015), es una referencia al pasado, al desarraigo; o, como expresó Gustavo Corrado (La Prensa, 13 de junio 2007), una referencia a valores y sentimientos: el honor, el amor, la soledad... Existe una relación entre las historias personales y la situación de crisis económica y social de la Argentina con la abundante producción de contenidos vinculados a un objeto cultural comercializable en el mercado global y que es caro a la identidad local, urbana y porteña (rioplatense).

\section{Notas:}

1. Antes de que se desarrollara este proceso hubo otros intentos débiles que no tuvieron la importancia ni la trascendencia de lo ocurrido a partir de la década de los noventa. En 1948, el Estado nacional transformó la orquesta de tango, creada en 1932 por Juan de Dios Filiberto, en la Orquesta Nacional de Música Argentina. En 1973, la misma orquesta fue bautizada con el nombre de su creador. Un tiempo después, en 1977, y por una iniciativa que había comenzado en 1965, se estableció primero por decreto municipal y después por decreto nacional el 11 de diciembre como Día Nacional del Tango.

2. Esta ley (24648/96) dice en su artículo primero: "Declárase como parte integrante del patrimonio cultural de la Nación a la música típica denominada 'tango' comprendiendo todas sus manifestaciones artísticas, tales como música, letra, danza y representaciones plásticas alusivas". El Decreto del Poder Ejecutivo 627/98 insta a cumplir y hacer cumplir la ley a los distintos ministerios y secretarías, reforzando lo ya promovido dos años antes. 3. En 1999, por la Ley 228, se creó la radio 92.7, con una programación destinada, íntegramente, a la emisión de música de tango y popular argentina. Más adelante, en el año 2005, la Ley 26046 estableció la Semana Nacional del Tango, comprendida entre los días 11 y 18 de diciembre de cada año. En 2009, el tango fue declarado Patrimonio Cultural Inmaterial de la Humanidad (Morel, 2009).

4. Nakked tango (1990, Leonard Schrader, coproducción USA-Suiza-Argentina-Japón; Gotan / Grupo Baires / Jade M / Praesens-Film / Sugarloaf Films Inc. / Towa. Hablada en inglés); Funes, un gran amor (1993, Raúl de la Torre, Argentina); El día que Maradona conoció a Gardel. Una fábula de héroes (1996, Rodolfo Pagliere, Argentina); Quereme así (piantao) (1997, Rodolfo Pagliere, Argentina); La lección de tango (1997, Sally Porter, coproducción Reino Unido-Francia-Alemania-Argentina); Tango, no me dejes nunca (1998, Carlos Saura, coproducción argentino-española); Sus ojos se cerraron (1998, Jaime Chavarri, coproducción Argentina-española).

5. Solo a modo de referencia: en al año 1998 a nivel de la ciudad de Buenos Aires, hay una referencia de un total de asistencia a salas de cine de 12.456.479; mientras que en el año 2001 llegaron a un total de 9.274 .758 (https://www.estadisticaciudad.gob.ar/ eyc/?p=23735).

6. El Instituto Nacional de Cine y Artes Audiovisuales (Ley 24377/94) funciona como ente autárquico dependiente de la Secretaría de Cultura del Ministerio de Cultura y Educación de la Nación. Tiene a su cargo el fomento y la regulación de la actividad cinema- 
tográfica en todo el territorio de la República y en el exterior en cuanto se refiere a la cinematografía nacional.

7. En 1988, en el Festival Internacional de Rotterdam, se creó el programa, cuya tarea era encargarse de las aportaciones económicas y técnicas destinadas a los ámbitos de la producción, posproducción y distribución de proyectos surgidos en regiones periféricas. 8. Tamara Falicov (citada en Soria, 2016, párr. 20) formula tres características a las que debe adherir un filme para ser considerado transnacional:

Una narrativa universalmente comprensible (si bien lo global debe tener cierta superposición con elementos locales); una narrativa y puesta en escena que no sean "muy globales" que resulten homogéneas; $y$, de manera inversa, una narrativa y una estética que no se desvíen hacia el camino de algo "muy local" o irreconocible.

9. Un ejemplo emblemático de la nostalgia y su representación es el filme Yo no sé que me han hecho tus ojos (Muñoz-Wolf, 2003).

10. Rodolfo Mederos (1940), bandoneonista, compositor, director, docente y arreglador de tango.

11. Pompeya es uno de los barrios de la ciudad de Buenos Aires. Está ubicado en la zona sur de la capital, de una importante tradición tanguera.

12. La letra de Garúa es de Enrique Cadícamo y la música de Aníbal Troilo, ambos destacados creadores. Fue grabado para la RCA Víctor en 1943.

13. A la manera casi detectivesca en que lo hace Sergio Wolf como protagonista del filme Yo no sé qué me han hecho tus ojos (Muñoz-Wolf, 2003).

\section{Bibliografía}

Alonso, M. (2016). Representaciones y miradas. El cine y el tango en la historia reciente (1990-2010). Actas VII Jornadas Nacionales y IV Jornadas Internacionales de Historia, Arte y Política. Tandil: Universidad Nacional del Centro de la Provincia de Buenos Aires. ISBN 978-950-658-394-1. Disponible en: https://dhtarte.files.wordpress.com/2015/03/ actas-jhap-2016.pdf

Alonso, M (2018) Cine y tango (1990-2010). Representaciones y memoria. X Jornadas de Sociología de la Universidad Nacional de La Plata. Institución de origen: Facultad de Humanidades y Ciencias de la Educación. ISSN: 2250-8465. Disponible en http://sedici. unlp.edu.ar/handle/10915/82030

Alonso, M. (2019). Tango and Cinema (1990-2010). Representations, Market and Politics. Identity Mediations in Latin American Cinemas and Beyond. Cultural Industries, Musical Flows and Transnational Discourses. En Gil Mariño, N. y Miranda, L. (comps.), Identity Mediations in Latin American Cinema and Beyond: Culture, Music and Transnational Discourses. Cambridge: Cambridge Scholars Publishing.

Amiot, J. (2018). El Fonds Sud Cinéma y el Nuevo cine argentino. Estudio de caso y problemáticas generales de la coproducción Europa/América Latina. Traduction de Lucía Belloro, pp. 80-91. En https://journals.openedition.org/cinelatino/4176 
Caletti Garciadiego, B. (2017). Cine ¿para quién? A 20 años de la Ley de Cine en Argentina. Imagofagia. Revista de la Asociación Argentina de Estudios de Cine y Audiovisual, No 15, ISSN 1852-9550. En https://ri.conicet.gov.ar/bitstream/handle/11336/45596/CONICET_ Digital_Nro.ff537d44-234a-499e-b0cc-427320e3d622_A.pdf?sequence=2\&isAllowed=y Campos Rabadán, M. (2012). El circuito de financiación de los cines latinoamericanos. Cinema d'amerique latine. Nro.20. En https://journals.openedition.org/cinelatino/667

Campos Rabadán, M. (2013). La América Latina de cine en construcción: implicaciones del apoyo económico de los festivales internacionales. Archivos de la Filmoteca, 71, 13 26, ISSN 0214-6606.

Campos Rabadán, M. (2016). Construcción y legitimación de los cines (trans)nacionales en el circuito internacional de festivales. El caso de América Latina [tesis doctoral]. Universidad Carlos III de Madrid. Disponible en http://hdl.handle.net/10016/23801

Cecconi, S. (2017). La crisis de 2001 y el tango juvenil: de la protesta política y social a las formas alternativas de organización y expresión. Estudios Sociológicos, Vol. 35 nro. 103, México, versión online ISSN 24486442, versión impresa ISSN 0185-4186.

Cecconi, S. (2014) Dilemas y tensiones en el proceso de patrimonialización del tango. En Margulis, M; Urresti, M; Lewin, $\mathrm{H}$ y otros, Intervenir en la cultura. Más allá de las políticas culturales. Buenos Aires: Biblos.

Marchini, J. (2007). El tango en la economía de la Ciudad de Buenos Aires. Buenos Aires, Observatorio de Industrias Culturales de la Ciudad de Buenos Aires.

Morel, H (1999). Los usos sociales del patrimonio cultural. En Aguilar Criado, E. (coord.) Patrimonio etnológico: nuevas perspectivas de estudio, Granada: Instituto Andaluz del Patrimonio Histórico, Serie Cuadernos, 227 p. ISBN 9788482660936.

Morel, H. (2009). El giro patrimonial del tango: políticas oficiales, turismo y campeonatos de baile en la ciudad de Buenos Aires. Cuadernos de Antropología Social, № 30, Facultad de Filosofía y Letras, UBA pp. 155-172 ISSN: 0327-3776.

Morel, H (2013). Buenos Aires, la meca del tango: procesos de activación, megaeventos culturales, turismo y dilemas en el patrimonio local. Revista Publicar, año XI, No XV, ISSN 0327-6627-ISSN 2250-7671.

Rocha, C. (2008). Cine despolitizado de principios de siglo: Bar El Chino y El abrazo partido. En Bulletin of Spanish Studies and Research on Spain Portugal, and Latin American, Volumen L138V, Number 3, Reino Unido.

Soria, C. (2016). Cine (trans)nacional: festivales de cine y marcas de identidad. Nuevo Mundo Nuevos Mundos. Disponible en https://journals.openedition.org/nuevomundo/69765

Sztulwark, D. (2019). La ofensiva sensible. Neoliberalismo, populismo y el reverso de lo político. Buenos Aires: Caja Negra Editora.

\section{Filmografía}

Abrazos, tango en Buenos Aires (2003). Daniel Rivas, Argentina Bar El Chino (2003). Daniel Burak. Argentina. 
Café de los maestros (2008). Miguel Kohan. Argentina-Estados Unidos-Brasil-Reino Unido. El sur de una pasión (2005). Cristina Fasulino. Argentina.

El tango de mi vida (2008). Hernán Belón. Argentina.

El Torcan (2009). Gabriel Arregui. Argentina.

El último aplauso (2009). Germán Kral. Argentina-Alemania-Japón.

El último bandoneón (2005). Alejandro Saderman. Argentina-Venezuela.

Garúa (2007). Gustavo Corrado. Argentina.

Homero Manzi, un poeta en la tormenta (2009). Eduardo Spagnuolo. Argentina.

La cantante de tango (2009). Diego Martínez Vignatti. Bélgica-Argentina-Francia-Alemania. Notas de tango (2001). Rafael Filippelli. Argentina.

Si sos brujo: una historia de tango (2005). Caroline Neal. Argentina.

Tango, un giro extraño (2005). Mercedes García Guevara. Argentina-Canadiense.

Yo no sé qué me han hecho tus ojos (2003). Lorena Muñoz y Sergio Wolf. Argentina.

\section{Referencias de leyes y decretos}

Decreto 627/98. Tango - Adóptense medidas tendientes a la consecución y permanente observancia de la Ley Nacional del Tango. Disponible en http://servicios.infoleg.gob.ar/ infolegInternet/anexos/50000-54999/51225/norma.htm

Ley 23980 (1991). Instituto Nacional del Tango - Su creación. Disponible en http://servicios. infoleg.gob.ar/infolegInternet/anexos/15000-19999/17074/norma.htm

Ley 24377 (1994). Fomento y Regulación de la Actividad Cinematográfica Nacional. Disponible en http://servicios.infoleg.gob.ar/infolegInternet/anexos/0-4999/767/norma.htm

Ley 24648 (1996). Tango. Patrimonio Cultural de la Nación - Declárese. Disponible en https://www.argentina.gob.ar/normativa/nacional/ley-24684-187292

Ley 228 (1999). Creación de la radio 92.7. Legislatura de la Ciudad Autónoma de Buenos Aires. Disponible en http://www2.cedom.gob.ar/es/legislacion/normas/leyes/ley228.html

Ley 130 (1999). Tango. Patrimonio cultural. Buenos Aires Ciudad. Disponible en https:// www.buenosaires.gob.ar/sites/gcaba/files/documents/ley_130.pdf

Ley 26046 (2005). Semana Nacional del Tango. Disponible en https://www.argentina.gob. ar/normativa/nacional/ley-26046-107624

\section{Referencias de medios periodísticos}

Arahuete, P. (28 de octubre de 2015). Entrevista a Caroline Neal: El tango es como una conversación sin el obstáculo de las palabras, una meditación sensual en movimiento. Cine Freaks. Disponible en https://cinefreaks.net/2015/09/28/entrevista-a-caroline-nealel-tango-es-como-una-conversacion-sin-el-obstaculo-de-las-palabras-una-meditacionsensual-en-movimiento/ 
Clarín (10 de diciembre de 2000). Informe especial: un nuevo negocio de exportación: una consultora estima que la argentina podría obtener 400 millones. Exportaciones de tango, un producto con futuro. Disponible en https://www.clarin.com/economia/exportacionestango-producto-futuro_0_SkFnHtgAKx.html

Halfon, M. (1 de febrero de 2009). El tango de mi vida rescata el tango oculto de la ciudad. Si lo sabe, cante. Página 12. Radar. Disponible en https://www.pagina12.com.ar/diario/ suplementos/radar/9-5091-2009-02-01.html

La Prensa (13 de junio de 2007). Tangos, crímenes, y bastante más. Disponible en http:// www.laprensa.com.ar/303884-Tangos-crimenes-y-bastante-mas.note.aspx

Martínez, A. C. (22 de marzo de 1997). Una opera prima hecha con pasión. La Nación. Disponible en https://www.lanacion.com.ar/espectaculos/una-opera-prima-hecha-conpasion-nid65663/

Montesoro, J. (14 de octubre de 2003). Opera prima. Pasado mañana llega "Bar El Chino". La Nación. Sección Espectáculos. Disponible en https://www.lanacion.com.ar/espectaculos/ cine/pasado-manana-llega-bar-el-chino-nid535455/

Página 12 (22 de noviembre de 2005). Dos películas tangueras en la cartelera porteña. Sueños de tango en un siglo XXI problemático y febril. Cultura. Espectáculos. Disponible en https://www.pagina12.com.ar/diario/suplementos/espectaculos/5-1087-2005-11-22.html

Pizarro, E (27 de julio de 2008). Tendencias. Tango S.A. La Nación. Suplemento de Cultura. Disponible en https://www.lanacion.com.ar/lifestyle/tango-sa-nid1032552/

Plaza, G. (20 de noviembre de 2003). Hoy se estrena "Abrazos": la cartelera 2003, llena de títulos que evocan el dos por cuatro. El tango se hace ver. La Nación. Sección Espectáculos. Disponible en https://www.lanacion.com.ar/espectaculos/cine/el-tango-se-hacever-nid546805/

Ranzani, O. (9 de noviembre de 2010). Diego Martínez Vignatti habla de su película la cantante de tango. La pasión en dos por cuatro Página 12. Cultura. Espectáculos. Disponible en https://www.pagina12.com.ar/diario/suplementos/espectaculos/5-19854-2010-11-09. html

Sendros, P. (3 de diciembre de 2009). Emotivo reencuentro en el bar El Chino. Ambito Financiero. Disponible en https://www.ambito.com/edicion-impresa/emotivo-reencuentroel-bar-el-chino-n3596440

\footnotetext{
Abstract: In this article we will discuss a corpus of films produced between 2001 and 2010 that refers to the topic of tango. We intend to review the relationship between the market, the forms of production and distribution of those films and the identities they build in their plots.

We will study the different sources of funding that they accessed to and the places of circulation, focusing especially on the international film festivals that, from the beginning of the eighties, added the role of producers to the traditional role of exhibitors, venturing into industrial work as well. (Soria, 2016; Amiot, 2018)
} 
The questions that guide the work are: where and how did Argentinian tango films circulate? To what extent did the technical and economic support provided by the various international organizations condition the contents of these films? What selection criteria existed when funding new projects and how did they impact on local productions? And what relationships can be established between funding and the identities/alterities that were built?

Keywords: identity - market - cinema - tango - audiovisual story.

Resumo: Neste artigo discutiremos um corpus de filmes produzidos entre 2001 e 2010 que abordam o tema do tango. Pretendemos rever a relação entre o mercado, as formas de produção e distribuição de tais filmes e as identidades que constroem em suas tramas. Estudaremos as diferentes fontes de financiamento que eles acessaram e os locais de circulação, focando principalmente nos festivais internacionais de cinema que, desde a primeira metade dos anos oitenta, acrescentaram à função tradicional de expositores a de produtores, aventurando-se também no trabalho industrial (Soria, 2016; Amiot, 2018). As questões que norteiam o trabalho são: onde e como circulam os filmes argentinos de tango? Até que ponto o apoio técnico e financeiro fornecido pelas diversas organizações internacionais condicionou o conteúdo desses filmes? Quais critérios de seleção existiam ao financiar novos projetos e como eles impactaram as produções locais? E quais relações podem ser estabelecidas entre o financiamento e as identidades/alterações que foram construídas?

Palavras chave: identidade - mercado - cinema - tango - história audiovisual.

[Las traducciones de los abstracts fueron supervisadas por el autor de cada artículo] 